U.S. Department

of Transportation

Federal Railroad

Administration

RR09-20

September 2009

\title{
Decreases in Collision Risk and Derailments Attributed to Changing At-Risk Behavior Process at Union Pacific
}

\section{SUMMARY}

Changing At-Risk Behavior (CAB) is a safety process that is being conducted at Union Pacific's San Antonio Service Unit (SASU) with the aim of improving road and yard safety. CAB is an example of a proactive safety risk-reduction method, called Clear Signal for Action (CSA), by the Federal Railroad Administration (FRA) Human Factors Program within the Office of Research and Development. CSA combines behavior-based safety, continuous improvement, and safety leadership development. With sponsorship from FRA, Behavioral Science Technology, Inc., is instructing and advising on the implementation of CAB.

Beginning in September 2005, CAB initially targeted improving practices associated with road-crew attention. Over two years since the start of this effort, SASU showed significant 72 percent drop in decertification rates, a proxy for collisions, that are likely to be related to crew attention, namely failure to stop for a red signal aspect, violation of main track authority, and speeding. The other service units in the same region showed no significant change in such decertifications (see Figure 1).

Beginning in October 2006, CAB expanded its focus to operations in the yard. At the time of this evaluation, there was a strong implementation at the Eagle Pass yard, a moderate implementation in the yards within the city of San Antonio, and no implementation at other yards in the service unit. Since CAB switching started, human-factors derailment rates decreased 69 percent (i.e., improved 319 percent) at the Eagle Pass yard. No significant changes occurred for the City of San Antonio or the non-CAB yards (see Table 1).

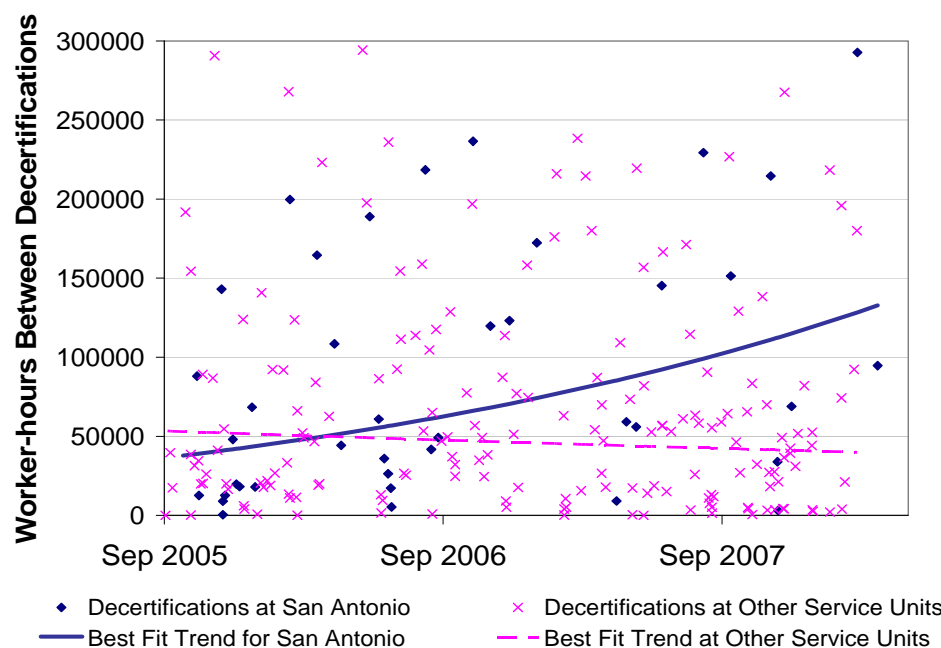

Figure 1. Decertifications at SASU versus other service units.
Table 1. Average Car-Moves Between Human-Factors Incidents at SASU Yards

\begin{tabular}{lccc}
\multicolumn{1}{c}{ Yard } & $\begin{array}{c}\text { Before } \\
\text { CAB }\end{array}$ & $\begin{array}{c}\text { During } \\
\text { CAB }\end{array}$ & $\begin{array}{c}\text { Percent } \\
\text { Improved }\end{array}$ \\
\hline $\begin{array}{l}\text { Eagle } \\
\text { Pass }\end{array}$ & 10,931 & 45,785 & $\mathbf{3 1 9 \% * *}$ \\
$\begin{array}{l}\text { San } \\
\text { Antonio } \\
\text { City }\end{array}$ & 8,939 & 11,733 & $31 \%$ \\
$\begin{array}{l}\text { Other } \\
\text { locations* }\end{array}$ & 457,997 & 752,190 & $64 \%$ \\
\hline
\end{tabular}

* Includes locations that have high traffic but little actual switching; thus the relatively high average moves between incidents both before and during $\mathrm{CAB}$.

** Statistically significant change $(p<0.05)$. 


\section{BACKGROUND}

In response to a series of major accidents on Union Pacific Railroad's (UP) San Antonio Service Unit (SASU), UP management, the Brotherhood of Locomotive Engineers and Trainmen (BLET), and the United Transportation Union (UTU), in collaboration with Research \& Development's (R\&D) Human Factors Program, instituted a new safety process called Changing At-Risk Behavior (CAB). To FRA, CAB is a demonstration of a Clear Signal for Action (CSA) process, a proactive employeedirected risk-reduction method that includes the following components:

- Behavior-based safety (BBS), where trained peers provide each other with safety-related, confidential, constructive feedback while working together.

- Continuous improvement, where data compiled by workers in the course of providing feedback is used to identify and implement corrective actions to improve safety.

- Safety leadership development, where managers are trained to effectively support the process.

The CAB process began in August 2005 with the initiation of regular peer-to-peer feedback sessions. $C A B$ initially focused on behaviors to improve alertness and teamwork for locomotive cab operations on the road under constraining signals, a situation that UP calls Cab Red Zone (CRZ), for which specific CRZ rules are in the General Code of Operating Rules. Fourteen months after its origination, the implementation broadened its focus to include safety in yard-switching operations.

Training workers on the BBS component has continued systematically, with over half of the workforce trained by November 2007. Safety leadership training has also been completed with SASU managers. In the fall of 2007, approximately 300 peer-to-peer feedback sessions were conducted each month across a transportation workforce of 1,100 , a rate below what was targeted by the steering committee but still effective. Other evaluations of $C A B$ indicated safety improvements in worker behaviors for the practices targeted by $C A B$ (see Research Results RR08-08) and in labormanagement relations. Management has been improving the work environment in response to data provided by $C A B$, reportedly spending $\$ 65,000$ in one month on one yard alone. Data provided by $\mathrm{CAB}$ also encouraged management at a corporate level to institute a policy to provide locomotives with air conditioning at the head end of all trains. With such strength in the implementation, one would expect to see improvements in safety from CAB.

\section{OBJECTIVES}

This paper presents part of a final evaluation of $C A B$ conducted from its start in 2005 until 2008. The paper reports changes in safety outcomes since $\mathrm{CAB}$ began, as indicated through analysis of corporate safety data on incidents in the yard and locomotive engineer decertifications, considered a proxy for road collisions.

\section{METHODS}

To assess changes in safety outcomes associated with $C A B$, the corporate data for locations with the $C A B$ process are contrasted with a "comparison location" that was not engaging in the CAB process, in order to separate effects due to regional or corporate changes regarding safety. With comparison locations available, the primary statistical analysis conducted concerned the performance at the $\mathrm{CAB}$ location relative to the comparison location. If the observed changes in safety at the $C A B$ location are different from those at the comparison location, it implies that some factor associated with only the $C A B$ location, such as the $C A B$ safety process itself, is specifically affecting the data. On the other hand, if the change observed is the same at both the $C A B$ and the comparison location, it raises the strong possibility that a factor common to both locations, such as a regional initiative, is responsible.

\section{Decertifications}

The new CRZ rules are intended to prevent collisions on the road. Such collisions, although potentially catastrophic, are too rare to assess statistically for the effects of CAB's road effort. Therefore, engineer decertifications were used as a proxy measure of collisions since they can be thought of as a close call of CRZ-related accidents. This includes decertifications for failure to stop for a red signal aspect, violating main track authority, and speeding. If CAB's road effort is effective, such decertification rates should decrease.

To separate regional and corporate effects from those of CAB, the performance of SASU on these decertifications is compared with that of other service units in the Southern Region for the same time period. To allow SASU decertifications to be compared with those for the other service units, decertifications are normalized with worker-hours.

However, rather than calculate the number of decertifications per 200,000 worker-hours per 
month, this evaluation instead calculates the number of worker-hours completed between decertifications. Worker-hours between decertifications can be thought of as the opposite of decertifications per worker-hours; that is, the more worker-hours that have elapsed between decertifications, the less frequent the decertifications per block of workerhours. This "upside-down" measure provides greater statistical sensitivity in the analysis, making it easier to detect true effects while controlling for spurious effects. It also means that higher scores represent greater safety.

\section{Yard Incidents}

The effect of CAB's later yard effort on safety is measured through yard incidents attributed to human factors. ${ }^{1}$ Yard incidents include collisions, fires, and derailments, the latter accounting for the large majority of the incidents. If CAB's yard effort is effective, these human-factors incident rates should decrease in the yard.

Unlike decertifications, the yards of other Southern Region service units could not be used for comparison because most of these service units had CSA-like processes in their own yards. However, CAB's yard effort was implemented to different degrees within the SASU. Eagle Pass yard had a strong implementation, while the yards in the City of San Antonio had a more moderate implementation, with their rate of peer-to-peer feedback sessions playing catch-up to that of Eagle Pass. Other SASU yards had no implementation at the time of this evaluation. Thus, Eagle Pass, the City of San Antonio, and other SASU yards can be compared for the effects of CAB. Safety factors common to the service unit, region, or company should affect all of these locations equally. Safety improvements due to CAB should affect Eagle Pass the most, followed by the City of San Antonio, with improvements for other yards having no effect.

Consistent with general UP practices, yard incidents were normalized on car-moves through the yards to allow comparisons across yards. Analogous to the statistical analysis conducted with worker-hours and decertifications, this evaluation uses the number of car-moves between incidents rather than the number of incidents per block of car-moves. More cars being moved between derailments represents greater safety.

\footnotetext{
1 Personal injuries in the yard are of course also a measure of safety-process effectiveness, but normalizing data at the yard level for injuries were not available for this evaluation.
}

\section{RESULTS}

\section{Decertifications Decreasing with CSA}

An improvement in decertification rates was detected only at the SASU location with the CSA process focusing on road operations. Over two years since the start of the CAB effort for the road, SASU showed a significant increase in worker-hours between the decertifications for failure to stop for a red signal aspect, violation of main track authority, and speeding ( $r=0.357, n=40, p=0.027$ ). The increase was equivalent to a 72 percent drop in the rate of decertifications. The other service units of the Southern Region showed no significant change in decertifications $(r=-0.078, n=180, p=0.300$; see Figure 1).

\section{Yard Incidents Decreasing with CSA}

An improvement in incident rates was detected only at the location with a strong CSA process for the yard. Only Eagle Pass experienced a significant increase in car-moves between incidents $(t(47)=$ 9.453, $p<0.0001$ ) from the start of CAB's effort for switching until a year later. The increase was equivalent to a 69 percent drop in the incident rate. The changes for the City of San Antonio and the non-CAB yards were not significant $(t(269)=0.029$, $p=0.9767$, and $t(113)=1.752, p=0.0824$, respectively; see Table 1 ). Some improvements at the City of San Antonio yards might have been expected, given their moderate CSA effort, but it should be noted that this comparison is over only 1 year, which may not be enough time for an implementation of such strength to build up enough feedback sessions to have an effect.

\section{CONCLUSIONS}

Overall, strong evidence exists that locations practicing CSA are becoming safer. SASU is improving on decertifications associated with CRZ rules, indicating a decreasing risk of collisions, while other service units in UP's Southern Region are not. Eagle Pass is improving on human-factors incidents, while other yard locations within SASU with weaker or absent CSA processes are not. Because these improvements are seen only at locations with CSA, they are more plausibly attributed to the advent of CSA than to other changes in the region or company.

Because of the design of this field evaluation, it is not possible to assess the relative impacts from each of the three components of CSA: BBS as practiced by workers, safety leadership as practiced by management, or continuous improvement as 
practiced by both. Instead, these results should be regarded as the joint impact of labor and management working together on safety.

\section{FUTURE DIRECTION AND ACTIVITIES}

Another CSA demonstration pilot is underway on the Livonia Service Unit, which is also in UP's Southern Region. This CSA effort is focused on yard work, so analyses are expected to focus on switching practices, yard injuries and incidents, and organizational culture.

\section{WANT MORE INFORMATION?}

For more details about CAB at SASU:

Clear Signal for Action Program Addresses Locomotive Cab Safety Related to Constraining Signals, May 2006, Research Results RR07-08.

Promising Evidence of Impact on Road Safety by Changing At-Risk Behavior Process at Union Pacific, June 2008, Research Results RR08-08

For findings from another CSA project:

Behavior-Based Safety at Amtrak-Chicago Associated with Reduced Injuries and Costs, March 2006, Research Results RR07-07.

Positive Safety Outcomes of Clear Signal for Action Program at Union Pacific Yard Operations, June 2008, Research Results RR08-09

Improvements in Labor-Management Relations Attributed to Changing At-Risk Behavior Process at Union Pacific, Research Results, in press.

These papers are available on the FRA Web site (http://www.fra.dot.gov).

\section{ACKNOWLEDGMENTS}

Behavioral Science Technology, Inc. (BST), a company that has implemented CSA-like programs in a broad range of industries, is instructing and advising on the implementation of CAB. BST's proprietary CSA method is called the Behavioral Accident Prevention Process (known as BAPP) ${ }^{\circledR}$.

This study would not have been possible without the cooperation of a large number of managers and employees at Union Pacific Railroad.
The authors would especially like to thank Brian Gorton, Michael Byars, and Kelvin Phillips for their considerable assistance, along with Lance Fritz, Joe Santamaria, Roby Brown, Michael Mitchell, Mark Barnum, Ted Lewis, Shane Keller, Ronald Tindall, Greg Burger, John Dunn, Russell Elley, Mike Araujo, Paul Dillon, Carl Eddington, Jose Gutierez, Wil Hardiman, Chad Jistel, Oscar "Doctor" Mayfield, Fernando Nanez, Pat Pino, Martin Vacca, Mario Valadez, and Andy Wright. Thanks also to George Wollard and Jay Finny of BST for providing education and insights into implementing CSA-type methods in the railroad industry. Along with Kelly Johnson and others at BST, George also gathered data for us from a survey customized to our requirements. Jonny Morell from NewVectors and Demetra Collia from the Bureau of Transportation Statistics provided additional technical assistance. Shuang Wu of Computer Sciences Corporation assisted in the processing and analyses of the data. The work is being performed under an interagency agreement between FRA's Human Factors R\&D Program and the Volpe National Transportation Systems Center's Human Factors Division.

\section{CONTACT}

Michael Coplen

Senior Evaluator, Director, Culture and Safety

Performance Studies, Human Factors Program

Federal Railroad Administration

Office of Research and Development

1200 New Jersey Ave., SE - Mail Stop 20

Washington, DC 20590

(202) 493-6346

Michael.Coplen@fra.dot.gov

Joyce Ranney and Michael Zuschlag

Human Factors Research and System Applications

Research and Innovative Technology Administration Volpe National Transportation Systems Center

55 Broadway, RTV-4G

Cambridge, MA 02142

(617) 494-2095, (617) 494-3250

Ranney@volpe.dot.gov, Zuschlag@volpe.dot.gov

KEYWORDS: railroad safety culture, behaviorbased safety (BBS), continuous improvement, safety leadership, Clear Signal for Action (CSA), observation-feedback, lessons learned

Notice and Disclaimer: This document is disseminated under the sponsorship of the United States Department of Transportation in the interest of information exchange. Any opinions, findings and conclusions, or recommendations expressed in this material do not necessarily reflect the views or policies of the United States Government, nor does mention of trade names, commercial products, or organizations imply endorsement by the United States Government. The United States Government assumes no liability for the content or use of the material contained in this document. 